\section{Problemas de violência ocupacional em um serviço de urgência hospitalar da Cidade de Londrina, Paraná, Brasil}

\author{
Occupational violence problems in an \\ emergency hospital in Londrina, Paraná, Brazil
}

\author{
${ }^{1}$ Centro de Educação \\ Profissional "Mater Ter \\ Admirabilis", Universidade \\ Norte do Paraná, \\ Londrina, Brasil. \\ 2 Escola de Enfermagem \\ de Ribeirão Preto, \\ Universidade de São Paulo, \\ Ribeirão Preto, Brasil. \\ Correspondência \\ E. S. Cezar \\ Centro de Educação \\ Profissional "Mater Ter \\ Admirabilis”, Universidade \\ Norte do Paraná. \\ Av. Rio de Janeiro 1643, \\ apto. 604, Londrina, PR \\ 86010-150, Brasil. \\ eliene.cezar@unopar.br
}

\begin{abstract}
Workplace violence is currently a worrying factor at many hospitals. The objectives of this study were to characterize the occupational violence problems detected by health workers in an emergency hospital. The study was exploratory and transversal, with a quantitative data approach. It took place at the emergency ward of a general hospital in Londrina, Paraná. The study population included 33 people from the nursing team and 14 medical doctors. Data were collected through interviews with health workers and staff managers, as well as assessment of violence records from the last seven years. $100 \%$ of nurses, $88.9 \%$ of technicians, $88.2 \%$ of nurse assistants, and $85.7 \%$ of doctors said that they had been victims of workplace violence, although not documented. The types of violence suffered included verbal assault (95.2\%) and moral and sexual battery (33.3\%). Preventive measures to reduce occupational violence should be applied.

Violence; Occupational Health; Health Personnel
\end{abstract}

Eliene Simões Cezar 1

Maria Helena Palucci Marziale 2

\section{Introdução}

A violência no trabalho é um problema observado em hospitais, principalmente em serviços de urgência onde os trabalhadores da equipe de saúde, ora atores, ora vítimas de atos violentos, estão reproduzindo e perpetuando situações de agressividade que vêm prejudicando a assistência prestada aos clientes e ocasionando o adoecimento pelo trabalho. Vários fatores podem interferir na violência ocupacional tais como: aspectos individuais dos trabalhadores (personalidade, formação); aspectos relacionados ao próprio ambiente de trabalho (estratégia organizacional, recursos humanos e materiais, sistema de comunicação); além de aspectos ligados à clientela atendida e social 1,2,3,4.

Segundo a Organização Mundial da Saúde (OMS) 5 (p. 3) "a violência é o uso intencional da força física ou do poder, real ou por ameaça, contra a própria pessoa, contra outra pessoa, ou contra um grupo ou comunidade que pode resultar, ou tem alta probabilidade de resultar, em morte, lesão, dano psicológico, alterações do desenvolvimento ou de privação”. Ela está constituída por incidentes nos quais os trabalhadores sofrem abusos, ameaças ou ataques em circunstâncias relacionadas com o seu trabalho, incluindo o trajeto, que colocam em perigo, implícita ou explicitamente, sua segurança, seu bem-estar ou sua saúde. 
No setor saúde, a violência tornou-se significativa pelas lesões físicas, psíquicas e morais que acarreta. É um problema da intersetorialidade na qual o campo médico-social se integra aceitando atender as vítimas da violência, e também deve colaborar na elaboração de estratégias de prevenção e superação dos problemas 3 .

O expressivo número de trabalhadores do setor de saúde que são atingidos pela violência em diversos países chamou a atenção da Organização Internacional do Trabalho (OIT) e de outras instituições que estabeleceram diretrizes para combater o medo, a humilhação, as agressões e os homicídios nos locais de trabalho 6 .

Visando a contribuir para a discussão do tema, este estudo teve como objetivos caracterizar os problemas de violência ocupacional a que estão expostos os médicos e trabalhadores de enfermagem no serviço de urgência hospitalar; levantar os problemas de violência identificados pela gerência da equipe médica e de enfermagem.

\section{Material e métodos}

Estudo exploratório, transversal, com abordagem quantitativa dos dados, realizado no serviço de urgência de um hospital geral de 204 leitos em Londrina, Paraná, Brasil, com 33 (100\%) trabalhadores de enfermagem (enfermeiros, técnicos e auxiliares de enfermagem) e 14 médicos, $56 \%$ da população alvo de 25 médicos que atuavam no serviço no período de 20 de outubro a 15 de novembro de 2004.

O projeto de pesquisa foi aprovado pelo Comitê de Ética em Pesquisa do hospital em estudo. Os trabalhadores consentiram em participar do estudo e assinaram o Termo de Consentimento Livre e Esclarecido.

Os dados foram coletados por meio das etapas descritas a seguir:

a) Primeira etapa - entrevista com os trabalhadores mediante um roteiro para caracterização dos trabalhadores, identificação dos fatores de riscos, violência sofrida e medidas usadas para preveni-las. O roteiro, validado por três pesquisadores na área da saúde do trabalhador, foi considerado satisfatório quanto à objetividade e conteúdo.

b) Segunda etapa - entrevista com os quatro gestores dos serviços de medicina e de enfermagem, e aplicação do workplace violence checklist 7 . O instrumento foi traduzido do inglês para o português, adaptado às peculiaridades dos serviços de urgência hospitalar brasileiro e submetido à avaliação de três pesquisadores da área de saúde do trabalhador que o consideraram adequado.

c) Terceira etapa - consulta aos casos de violência registrados de janeiro de 1998 a outubro de 2004 e leitura dos prontuários dos trabalhadores vitimados para identificar as conseqüências das agressões.

Os dados foram inseridos em banco do programa SPSS for Windows versão 8.0 (SPSS Inc., Chicago, Estados Unidos) e tratados por estatística descritiva.

\section{Resultados e discussão}

Os resultados revelam que $12(85,7 \%)$ dos médicos, 7 (100\%) dos enfermeiros, 8 (88,9\%) dos técnicos em enfermagem e $15(88,2 \%)$ dos auxiliares de enfermagem foram vítimas de violência ocupacional, $88,9 \%$ dos quais nos últimos doze meses. Para analisar as variáveis "violência e categoria profissional" foi utilizado o teste de Fisher, e o resultado encontrado ( $\mathrm{p}=0,9218$ ) indica não haver diferença significativa entre as variáveis.

Os trabalhadores agredidos eram 26 (55,3\%) do sexo masculino e $21(44,7 \%)$ do sexo feminino. Quando correlacionadas a variável sexo e a ocorrência de violência foi constatado que 24 (92,3\%) homens e 18 (85,7\%) mulheres sofreram violência ocupacional, porém não foi encontrada associação estatística significativa entre as variáveis $(\mathrm{p}=0,6441)$. Esses resultados diferem dos dados descritos na literatura 2,8,9, que informam serem as mulheres mais vulneráveis à violência.

As formas de violência apontadas pelos médicos foram: agressões verbais 12 (100\%), roubo $4(33,3 \%)$, competição entre os colegas 3 (25\%), assédio sexual 3 (25\%), agressões físicas $2(16,7 \%)$ e assédio moral $2(16,7 \%)$.

As formas de violência identificadas pelos trabalhadores de enfermagem foram: agressões verbais 28 (93,3\%), assédio moral 9 (30\%), competição entre colegas 7 (23\%), agressões físicas $5(16,7 \%)$, roubos $4(13,3 \%)$, discriminação social $1(3,3 \%)$ e maus tratos $1(3,3 \%)$.

O enfermeiro tem sido a principal vítima de violência nos locais de prestação de trabalho ${ }^{3}$. Diante dessa realidade, a Ordem dos Enfermeiros manifesta a sua preocupação, lançando um alerta às entidades para adoção de medidas que salvaguardem a integridade física e psicológica dos profissionais de saúde em geral e, particularmente, dos enfermeiros 10 .

Investigando-se as formas de violência no mundo do trabalho de enfermagem em um serviço de urgência clínica 11, foi constatado que a violência opera pelas vias: estrutural/institu- 
cional e comportamental/relacional que se explicitam em quatro tipos de violência: estrutural (imposição de sobrecarga física e mental aos trabalhadores); repressiva (negação do direito de exercer com segurança as atividades assistenciais); alienação (obstaculização aos trabalhadores de usufruir o prazer de realizações profissionais e de ser valorizado socialmente); e violência clássica (revelada nas agressões físicas e verbais da equipe e de usuários).

Essas violências desencadeiam e perpetuam "violências menores": práticas profissionais traumatizantes, negligências, imperícias, atendimento fragmentado, baixa auto-estima, entre outras. Essas, por sua vez, apóiam e fortificam as violências estruturais e comportamentais, numa circularidade viciosa, que impõe o entendimento de seus modos operatórios para os necessários enfrentamentos com a finalidade de romper o processo e favorecer a auto-realização profissional e humana dos trabalhadores de enfermagem e da saúde 11 .

Em relação à identificação do agressor, os trabalhadores elegeram o paciente como principal agressor $(57,1 \%)$, seguido pelo acompanhante $(54,8 \%)$. Na opinião da maioria dos profissionais, essa violência é motivada pelas precárias condições de atendimento ao público devido às péssimas condições de trabalho e à desigualdade social vigente no país. Os pacientes embora considerados muitas vezes como agressores, são também vítimas da inadequada assistência oferecida.

O local de trabalho foi considerado pelos trabalhadores, de todas as categorias profissio- nais, como parcialmente seguro para o desenvolvimento de suas atividades, porém a maioria já sofreu algum tipo de violência no trabalho, as quais tiveram como conseqüências sintomas emocionais tais como: raiva, tristeza, irritação, ansiedade e humilhação, que podem interferir sobre a condição de saúde. Esses resultados corroboram com o estudo realizado na Suécia, onde os trabalhadores de saúde relataram com maior freqüência os sintomas: irritação, raiva, medo do agressor, incapacidade e a humilhação como as conseqüências da violência ocupacional para com a sua saúde 12. Os efeitos dos maus tratos e as violências são inquietantes e compreendem uma gama de conseqüências provenientes dos atos, que incluem desde a lesão física, depressão, temor, estresse, perda da auto-estima, entre outros, até o comprometimento da qualidade dos cuidados prestados 8 .

Na Tabela 1 são apresentados os fatores predisponentes à violência ocupacional na situação estudada.

Em estudo realizado no Rio de Janeiro, em dois serviços de emergência, constatou-se que os atos de violência ocorriam por demora no atendimento às exigências dos familiares para que o paciente fosse atendido imediatamente e com tratamento especial 13. Esses fatores foram identificados também no hospital de Londrina como predisponentes a atos de violência.

Constatou-se que $43(91,4 \%)$ dos trabalhadores consideram importante o registro da violência ocupacional; no entanto, poucos regis-

\begin{tabular}{|c|c|c|c|c|c|c|c|c|c|c|}
\hline \multirow[t]{3}{*}{ Fatores de risco } & \multicolumn{10}{|c|}{ Categoria profissional } \\
\hline & \multicolumn{2}{|c|}{ Médico } & \multicolumn{2}{|c|}{ Enfermeiro } & \multicolumn{2}{|c|}{$\begin{array}{l}\text { Técnico de } \\
\text { enfermagem }\end{array}$} & \multicolumn{2}{|c|}{$\begin{array}{l}\text { Auxiliar de } \\
\text { enfermagem }\end{array}$} & \multicolumn{2}{|c|}{ Total } \\
\hline & $\mathrm{n}$ & $\%$ & $\mathrm{n}$ & $\%$ & $\mathrm{n}$ & $\%$ & $\mathrm{n}$ & $\%$ & $\mathrm{n}$ & $\%$ \\
\hline Pacientes violentos & 9 & 64,3 & 4 & 7,1 & 7 & 77,8 & 13 & 76,5 & 33 & 70,2 \\
\hline $\begin{array}{l}\text { Falta de pessoal treinado para lidar } \\
\text { com situações violentas }\end{array}$ & 7 & 50,0 & 5 & 1,4 & 6 & 66,7 & 5 & 29,4 & 23 & 48,9 \\
\hline Sobrecarga de pacientes & 8 & 57,1 & 4 & 57,1 & 5 & 55,6 & 5 & 29,4 & 22 & 46,8 \\
\hline Quartos e corredores superlotados & 7 & 50,0 & 3 & 42,9 & 7 & 77,8 & 4 & 23,5 & 21 & 44,7 \\
\hline Ambiente estressante (carga mental de trabalho) & 8 & 57,1 & 4 & 57,1 & 6 & 66,7 & 3 & 17,6 & 21 & 44,7 \\
\hline $\begin{array}{l}\text { Mau atendimento tornando-se fonte } \\
\text { de revolta de pacientes }\end{array}$ & 4 & 28,6 & 4 & 57,1 & 5 & 55,6 & 5 & 29,4 & 18 & 38,3 \\
\hline Filas de espera longas & 8 & 57,1 & 2 & 28,6 & 3 & 33,3 & 4 & 23,5 & 17 & 36,2 \\
\hline Equipamentos e materiais insuficientes e inadequados & 3 & 21,4 & 3 & 42,9 & 5 & 55,6 & 3 & 17,6 & 14 & 29,8 \\
\hline Equipe com escassez de trabalhadores & 6 & 42,9 & 2 & 28,6 & 3 & 33,3 & 3 & 17,6 & 14 & 29,8 \\
\hline
\end{tabular}

Nota: mais de uma resposta foi emitida pelos trabalhadores. 
tram as ocorrências. Dentre os episódios de violência notificados, ressaltam-se os casos de duas auxiliares de enfermagem mordidas por pacientes, uma estagiária agredida no crânio com um suporte de soro e um agente comunitário atingido com um pedaço de madeira.

Os problemas de violência identificados pelos gestores foram: comportamentos violentos contra a equipe de trabalho (principalmente agressão verbal) e insegurança do local de trabalho (não há barreiras físicas ou sistemas de segurança, nem detectores de metais e profissional de segurança no local). Dois gestores referiram que a violência é aceita como "parte do trabalho" por alguns supervisores e trabalhadores.

Segundo os gestores do serviço de enfermagem, os trabalhadores não são treinados para reconhecer e lidar com comportamentos violentos; um gestor informou que esse tipo de treinamento é proporcionado à equipe médica. A capacitação dos trabalhadores para detectar e evitar situações de risco e adotar posturas e procedimentos adequados diante da violência reduz a possibilidade de conseqüências graves, e certas preparações psicológicas podem reduzir as conseqüências psíquicas posteriores ao evento 14 .

Resumo

A violência no trabalho é um fator atualmente preocupante nos hospitais. Este estudo teve como objetivos caracterizar os problemas de violência ocupacional, detectados pelos trabalhadores da equipe de saúde do serviço de urgência hospitalar. Estudo exploratório e transversal, com abordagem quantitativa dos dados, foi realizado no serviço de urgência de um hospital geral da Cidade de Londrina, Paraná, Brasil. População composta por 33 trabalhadores da equipe de enfermagem e 14 médicos. Dados coletados por meio de entrevistas realizadas com os trabalhadores e com os gestores do serviço médico e de enfermagem, e consulta aos registros de violência dos últimos sete anos. Os resultados mostraram que $100 \%$ dos enfermeiros, $88,9 \%$ dos técnicos, 88,2\% dos auxiliares de enfermagem e 85,7\% dos médicos referiram ter sido vítimas de atos de violência no trabalho, embora não registradas. Tipo de violência sofrida: 95,2\% agressão verbal; 33,3\% por assédio moral e assédio sexual, respectivamente. Medidas preventivas para a violência ocupacional devem ser implementadas.

Violência; Saúde Ocupacional; Pessoal de Saúde

\section{Considerações finais}

Os resultados obtidos mostram que no ambiente estudado os trabalhadores estão expostos a vários fatores de risco de violência ocupacional e não estão preparados para lidar com eles. Assim, medidas devem ser implementadas para a prevenção de atos violentos tais como: capacitar os trabalhadores para o enfrentamento de situações críticas e para a prevenção de atos violentos de pacientes, familiares ou da própria equipe de saúde; melhorar as condições de trabalho com número adequado de recursos humanos e materiais; instalar dispositivos de segurança, impedir a entrada de pessoas armadas no interior do serviço; contratar profissional de segurança para as portarias; melhorar acomodação para os pacientes e acompanhantes; informar o motivo da demora no atendimento; criar um protocolo sistemático de registro das formas de violência ocupacional; formar um comitê multidisciplinar; e implantar um programa de prevenção de violência para o hospital, baseado nas diretrizes da OIT e OMS.

\section{Colaboradores}

E. S. Cezar foi responsável pela concepção e planejamento do projeto de pesquisa, obtenção ou análise e interpretação dos dados e redação e revisão crítica. M. H. P. Marziale foi responsável pela concepção e planejamento do projeto de pesquisa, análise e interpretação dos dados e revisão crítica.

\section{Agradecimentos}

A Profa. Dra. Jacinta Ludovico Zamboti do Departamento de Estatística e Matemática Aplicada da Universidade Estadual de Londrina, pela colaboração na análise estatística dos dados. 


\section{Referências}

1. Consejo Internacional de Enfermeras. La violencia. Epidemia mundial. Boletín del CIE; 1999. http:// www.icn.ch/matters_violencesp.htm (acessado em 19/Fev/2004).

2. Machado JMH, Gomez CM. Acidentes de trabalho: uma expressão da violência social. Cad Saúde Pública 1994; 10 Suppl 1:74-87.

3. National Institute for Occupational Health/Centers for Disease Control and Prevention. Violence occupational hazards in hospitals. http:/ /www. cdc.gov/niosh/2002-101.html (acessado em 29/ Mar/2004).

4. Di Martino V. Workplace violence in the health sector - country case studies (Brazil, Bulgarian, Lebanon, Portugal, South África, Thailand, and an additional Australian study). http://www.ilo. org/public/english/bureau/inf/pr/2002/49.htm (acessado em 04/Out/2004).

5. Organización Mundial de la Salud. Informe mundial sobre la violencia y la salud. Genebra: Organización Mundial de la Salud; 2002.

6. Organización Internacional del Trabajo/Organización Mundial de la Salud. Diretrices marco para afrontar la violencia laboral en el sector de la salud. http://www.icn.ch/SEWViolenceguidelineSP.pdf (acessado em 02/Mar/2004).

7. Occupational Safety and Health Administration, U.S. Department of Labor. Workplace violence checklist. http://www.osha.gov/SLTC/etools/hos pital/hazards/workplaceviolence/viol.html (acessado em 19/Fev/2004).
8. Minayo MCS. Violência como indicador de qualidade de vida. Acta Paul Enfermagem 2000; 13:15980.

9. Meneghel, SN; Barbiani R; Steffen H. et al. Impacto de grupos de mulheres em situação de vulnerabilidade de gênero. Cad Saúde Pública 2003; 19:955-63.

10. Ordem dos Enfermeiros de Portugal. Violência sobre enfermeiros - 2002. http://www.ordemenfermeiros.pt $/$ ?pgnoticias_comp\&id=29\&act $=0$ (acessado em 20/Nov/2004).

11. Costa ALRC. As múltiplas formas de violência no trabalho de enfermagem: o cotidiano de trabalho no setor de emergência e urgência clínica de um hospital público [Tese de Doutorado]. Ribeirão Preto: Escola de Enfermagem de Ribeirão Preto, Universidade de São Paulo; 2005.

12. Moreno LC. Violência e capacidade para o trabalho entre trabalhadores de enfermagem [Dissertação de Mestrado]. Campinas: Universidade Estadual de Campinas; 2004.

13. Deslandes SF. Violência no cotidiano dos serviços de emergências: representações, práticas, interações e desafios [Tese de Doutorado]. Rio de Janeiro: Escola Nacional de Saúde Pública, Fundação Oswaldo Cruz; 2000.

14. Mendes R. Patologia do trabalho. São Paulo: Editora Atheneu; 2003.

Recibido el 08/Dic/2004

Versión final presentada el 31/Oct/2005

Aprobado el 12/Dic/2005 